\title{
The Impact of Integrating Oral Health Education into a Medical Curriculum
}

\author{
Sang E. Park ${ }^{a}$ R. Bruce Donoff ${ }^{b}$ Fidencio Saldana ${ }^{c}$ \\ ${ }^{a}$ Office of Dental Education, Harvard School of Dental Medicine, ${ }^{b}$ Harvard School of Dental Medicine, Office of the \\ Dean, and ${ }^{\mathrm{C}}$ Office of Student Affairs, Harvard Medical School, Boston, MA, USA
}

\section{Keywords}

Oral health · Medical education · Interprofessional

education $\cdot$ Predoctoral education

\begin{abstract}
Objective: The purpose of this study was to evaluate our pilot program incorporating oral health education into the medical curriculum by evaluating students' perspectives on the oral health curriculum. Subjects and Methods: Two hundred second-year students were asked to fill in a presession survey online regarding their familiarity with basic oral health concepts and their comfort level with performing oral examinations, and a postsession survey on paper that repeated the presession questions and added questions on the effectiveness of the session. Results: Of the 200 students, 164 (82\%) participated in the surveys. The pre- and postsurvey results showed that the session helped students become more comfortable with performing oral examinations and recognizing risks for periodontal disease, with an increase from $40(27 \%)$ to $119(82 \%)$ and 51 (35\%) to $124(86 \%)$, respectively. Conclusion: In this study, the oral health education session contributed to an increase in student awareness and understanding of oral health. Considering the reported effectiveness of the interactive session on student comfort with performing a basic clinical examination, this model shows promise for further use in other institutions.
\end{abstract}

(c) 2016 S. Karger AG, Basel

\begin{tabular}{ll}
\hline KARGER & ( 2016 S. Karger AG, Basel \\
$\begin{array}{l}\text { E-Mail karger@karger.com } \\
\text { www.karger.com/mpp }\end{array}$ & $\begin{array}{l}\text { This is an Open Access article licensed under the terms of the } \\
\text { Creative Commons Attribution-NonCommercial 3.0 Un- } \\
\text { ported license (CC BY-NC) (www.karger.com/OA-license), } \\
\text { applicable to the online version of the article only. Distribu- } \\
\text { tion permitted for non-commercial purposes only. }\end{array}$
\end{tabular}

\section{Introduction}

An education process should include a learning environment that encourages students to learn collaboratively by applying basic biomedical foundations to solving patient cases [1]. As patient care involves a multidisciplinary and interprofessional environment with a team of health care providers, it is critical in early medical and dental education to introduce students to an interprofessional education program [1].

Primary care medical professionals - which include primary care physicians, nurse practitioners, behavioral care providers, pharmacists, physician assistants, and registered nurses - receive very little training in the treatment of oral health problems or the maintenance of good oral health even though they are more numerous than dentists and should be trained to address oral care disparities [2-4]. Clinicians across the entire medical profession can play a major role in improving access to oral care for vulnerable populations by providing preventive care, such as oral hygiene instructions, nutrition counseling, smoking cessation assistance, and even fluoride applications $[5,6]$. The integration of oral health into medical care will reduce health care costs as well as improve the quality of life for many, especially for patients with chronic diseases [7].

Separation of medical and dental education has serious negative implications in terms of delivery of care. 
Oral health education has been lacking in medical school curricula historically $[8,9]$. A national survey of 88 medical schools in the USA showed that $10.2 \%$ did not offer any curriculum in oral health [10]. In that study, medical schools with a dental school or residency were not related to the number of hours of oral health education. Mouradian et al. [6] stated that physicians could be instrumental in preventing oral diseases but lack the knowledge to play an active role. It is important to expose students to patients with oral and systemic medical conditions throughout the entire curriculum. The educational experience could help provide the tools for our future health care professions to serve the oral health needs of our patient population and furthermore the general public.

The Harvard School of Dental Medicine (HSDM) and Harvard Medical School (HMS) offered a central oral health program in the medical school curriculum as part of the Patient-Doctor course, beginning a new initiative to expose medical students to the concept of oral health. The course teaches the fundamental skills of the medical interview and physical examination across several different branches of medicine to prepare students for their clinical clerkships. Medical and dental students at Harvard take courses together as part of their education; however, in previous years, the focus of the combined courses was on providing the dental students with foundational medical knowledge before they began to concentrate on dentistry. The pilot program sought to incorporate oral health into one session of the Patient-Doctor course by introducing the medical students to the intraoral and extraoral examination as performed by dental professionals and raise the students' awareness of the increasingly evident links between oral health and systemic health. In this effort, the HSDM and HMS offered a central oral health program in the medical school curriculum as part of the Patient-Doctor course to develop an oral health intervention training program. The purpose of this study was to evaluate our pilot program by evaluating students' perspectives on the oral health curriculum at HMS.

\section{Subjects and Methods}

This study was approved by the Institutional Review Board at HMS and the HSDM. In the fall of 2014, HMS and the HSDM presented the first Oral Health Session in the Patient-Doctor II course.

The Oral Health Session was designed to include the entire second-year class at HMS, comprising 165 second-year medical students and 35 second-year dental students. We do not separate the medical and dental students in the courses they take together, and the data were collected as part of their course feedback. An overview of oral anatomy and the experience of performing an oral
Table 1. Learning objectives for the central session on oral health

1. Introduction to causes, prevention, and signs of dental caries

2. Introduction to causes and prevention of periodontal disease

3. Recognize that oral health is reflective of and linked to systemic health

4. Recognize normal intraoral and extraoral anatomy and general diagnostic concerns

5. Learn to conduct a head and neck, intraoral, and extraoral examination

examination in a hybrid of lecture, flipped classroom (in which students review basic concepts before class and spend class time on group activities to reinforce those concepts), and problem-based learning tutorial case (in which small groups of 8-10 students, each with a faculty or postdoctoral student mentor, are presented with a clinical case and discuss potential findings, issues, and treatments) formats. The specific learning objectives are shown in Table 1. Students were provided with a head and neck intraoral and extraoral examination video to view before the class time and a precourse survey. The HSDM faculty members presented lectures on basic oral anatomy and oral health's relation to systemic health, as well as the social aspects of oral health and dental treatment. Following the lectures, HSDM faculty supervised small-group exercises (10 students per group), which included a tutorial case study and hands-on oral examinations by the medical and dental students. Students were asked to fill out a postsession questionnaire at the end of the session. Students and tutorial leaders were provided with protective equipment (eye protection, gloves, and gowns) and materials (gauze and disposable mirrors) for the oral examination portions of the small-group session. Students were also given toothbrushes, toothpaste, and dental floss as part of oral hygiene instructions upon completion of the session.

\section{Results}

One hundred forty-six students completed the presession survey, and 145 students completed the postsession survey. Based on the postsession survey results, all respondents found the session to be helpful in raising their awareness of basic oral health issues and 135 (82\%) respondents were comfortable with performing oral examinations. The lecture on the social aspects of oral health care was particularly well received.

The responses for questions on basic oral health issues and oral examinations on the presession and postsession surveys are given in Table 2. Major findings from the presession data are that $51(35 \%)$ students were very or somewhat familiar with the causes and prevention of periodontal disease before the session, and this number increased to $124(86 \%)$ students after the session. Also, 40 (27\%) students were very or somewhat comfortable per-
Med Princ Pract 2017;26:61-65 DOI: $10.1159 / 000452275$
Park/Donoff/Saldana 
Table 2. Presession and postsession survey results for repeated questions

\begin{tabular}{|c|c|c|c|c|}
\hline Question & Category & Presurvey $^{\mathrm{a}}$ & Postsurvey $^{\mathrm{b}}$ & Standard deviation \\
\hline \multirow{5}{*}{$\begin{array}{l}\text { Are you familiar with the causes, } \\
\text { prevention, and signs of dental caries? }\end{array}$} & Very & $24(16)$ & $55(38)$ & \multirow{5}{*}{$\begin{array}{l}56.049(\mathrm{p}<0.001 \\
\text { d.f. } 4)\end{array}$} \\
\hline & Somewhat & $54(37)$ & $72(50)$ & \\
\hline & Neutral & $11(8)$ & $12(8)$ & \\
\hline & Not Very & $39(27)$ & $5(3)$ & \\
\hline & Not at All & $15(10)$ & 0 & \\
\hline \multirow{5}{*}{$\begin{array}{l}\text { Are you familiar with the causes and } \\
\text { prevention of periodontal disease? }\end{array}$} & Very & $23(16)$ & $39(27)$ & \multirow[t]{5}{*}{$89.393(\mathrm{p}<0.001)$} \\
\hline & Somewhat & $28(19)$ & $85(59)$ & \\
\hline & Neutral & $15(10)$ & $11(8)$ & \\
\hline & Not Very & $48(33)$ & $10(7)$ & \\
\hline & Not at All & $31(21)$ & 0 & \\
\hline \multirow{5}{*}{$\begin{array}{l}\text { Are you aware of links between } \\
\text { tobacco use and oral cancer? }\end{array}$} & Very & $70(48)$ & $76(52)$ & \multirow[t]{5}{*}{$6.431(\mathrm{p}=0.169)$} \\
\hline & Somewhat & $57(39)$ & $60(41)$ & \\
\hline & Neutral & $9(6)$ & $3(2)$ & \\
\hline & Not Very & $4(3)$ & $5(3)$ & \\
\hline & Not at All & $3(2)$ & 0 & \\
\hline \multirow{5}{*}{$\begin{array}{l}\text { Are you aware of the importance of } \\
\text { oral health screening? }\end{array}$} & Very & $64(44)$ & $109(75)$ & \multirow[t]{5}{*}{$38.018(\mathrm{p}<0.001)$} \\
\hline & Somewhat & $62(42)$ & $37(26)$ & \\
\hline & Neutral & $13(9)$ & 0 & \\
\hline & Not Very & $4(3)$ & 0 & \\
\hline & Not at All & $3(2)$ & 0 & \\
\hline \multirow{5}{*}{$\begin{array}{l}\text { Can you recognize risks for oral } \\
\text { disease? }\end{array}$} & Always & $8(5)$ & $30(21)$ & \multirow[t]{5}{*}{$75.861(\mathrm{p}<0.001)$} \\
\hline & Sometimes & $55(38)$ & $99(68)$ & \\
\hline & Neutral & $30(21)$ & $14(10)$ & \\
\hline & Not Often & $46(32)$ & $3(2)$ & \\
\hline & Never & $7(5)$ & 0 & \\
\hline \multirow{5}{*}{$\begin{array}{l}\text { Are you comfortable conducting an } \\
\text { oral examination? }\end{array}$} & Very & $16(11)$ & $43(30)$ & \multirow[t]{5}{*}{$106.345(\mathrm{p}<0.001)$} \\
\hline & Somewhat & $24(16)$ & $76(52)$ & \\
\hline & Neutral & $16(11)$ & $17(12)$ & \\
\hline & Not Very & $45(31)$ & $8(6)$ & \\
\hline & Not at All & $44(30)$ & $1(1)$ & \\
\hline \multirow{5}{*}{$\begin{array}{l}\text { Are you comfortable providing basic } \\
\text { oral health information to patients? }\end{array}$} & Very & $21(14)$ & $49(34)$ & \multirow[t]{5}{*}{$70.469(\mathrm{p}<0.001)$} \\
\hline & Somewhat & $38(26)$ & $75(52)$ & \\
\hline & Neutral & $14(10)$ & $14(10)$ & \\
\hline & Not Very & $49(34)$ & $7(5)$ & \\
\hline & Not at All & $21(14)$ & $2(1)$ & \\
\hline \multirow{5}{*}{$\begin{array}{l}\text { How important is oral health to } \\
\text { overall health and well-being? }\end{array}$} & Very & $107(73)$ & $120(83)$ & \multirow[t]{5}{*}{$3.798(\mathrm{p}=0.434)$} \\
\hline & Somewhat & $29(20)$ & $20(14)$ & \\
\hline & Neutral & $6(4)$ & $4(3)$ & \\
\hline & Not Very & $1(1)$ & $1(1)$ & \\
\hline & Not at All & $3(2)$ & $1(1)$ & \\
\hline \multirow{5}{*}{$\begin{array}{l}\text { How important is it for primary care } \\
\text { health professionals to collaborate } \\
\text { with dentists? }\end{array}$} & Very & $103(71)$ & $122(84)$ & \multirow[t]{5}{*}{$14.858(\mathrm{p}=0.005)$} \\
\hline & Somewhat & $32(22)$ & $21(14)$ & \\
\hline & Neutral & $6(4)$ & 0 & \\
\hline & Not Very & $3(2)$ & 0 & \\
\hline & Not at All & $2(1)$ & 0 & \\
\hline
\end{tabular}

Values are presented as numbers (\%) unless otherwise stated. ${ }^{\mathrm{a}} \mathrm{n}=146 .{ }^{\mathrm{b}} \mathrm{n}=145$. 
forming an oral examination before the session, versus 119 (82\%) students after the session. All 146 (100\%) students who participated were very or somewhat aware of the importance of oral health screenings.

\section{Discussion}

The pre- and postsurvey results showed that the oral health education session in the medical curriculum contributed to an increase in student awareness and understanding of the Oral Health Session course. It was also observed that students expressed interest in understanding the important link between oral and systemic health.

The Patient-Doctor course is designed to prepare students for clinical clerkships and focuses on establishing the patient-doctor relationship through the medical interview and physical examination. Although the course covers several branches of medicine, it had not included oral health in previous years.

Clinicians across the entire medical profession are invaluable assets in the prevention and detection of oral disease. An oral health education program is an important initiative to further develop educational collaboration between health professions and incorporate curricular content on the interaction of oral and systemic conditions.

Oral health is integral to systemic health, and an educational curriculum should reflect the need for collaboration among health care professionals for optimum patient care. Interprofessional training opportunities at the predoctoral level are important as medical education becomes more focused on the whole patient. Studies support the need for more interdisciplinary programs and interprofessional education in the curricula [11-15].

Not only do dental and medical educations share a foundation in basic biomedical science, but also the literature is replete with evidence that dental and oral diseases have associated systemic health problems and oral health is inextricably connected to physical health, quality of life, and disease prevention [14-20]. A lack of oral health has been shown to be associated with negative health outcomes including respiratory disease, cardiovascular disease, diabetes, stroke, and adverse pregnancy outcomes [4, 19, 21-23].

The project exposed the second-year medical students and dental students to the concept of oral health as it relates to systemic health and the intraoral and extraoral physical examination as conducted by dental professionals. A survey of US medical schools that offer curriculum hours in oral health found that while topics such as oral cancers were covered in $81.7 \%$ of the schools, only $10.0 \%$ taught hands-on skills [10]. To the question asking how comfortable students were conducting an oral examination, $82 \%$ of HMS and HSDM students responded positively after the session, compared with $27 \%$ before the experience. Considering the reported effectiveness of the interactive session on student comfort with performing a basic clinical examination, this model shows promise for further use in other institutions.

HMS and the HSDM are currently redesigning their curricula to meet new standards and explore new pedagogical methods and opportunities. Oral health education is an important step to support interprofessional education in the health care professions and to promote a collaborative learning environment in medical school. The interprofessional Oral Health Session for the secondyear students helped to expose the medical students to some basic concepts of oral health by dental school faculty, small-group discussions, and hands-on exercises. The initial feedback from the students was almost entirely positive.

Additional work is underway currently to integrate oral health education into the new medical school curriculum through introduction of interprofessional educational opportunities. Medical students could be invited to attend the third-year dental student case presentations and be asked to consider the medical implications of a patient undergoing extensive dental treatment. This would both reinforce the link between oral and systemic health and provide opportunities for peer-to-peer learning through small-group discussion.

Students found the tutorial case discussion to be the least useful of the sessions. This may be a result of the case selected; the hypothetical patient involved an edentulous case. However, the purpose of the tutorial session was to tie some potential findings of an oral examination to systemic medical conditions, and analysis of the survey data shows that this was accomplished.

While small-group tutorial cases are a regular part of both the HMS and the HSDM curricula, 20 HSDM faculty members were required to lead small-group sessions for the combined medical and dental students in a problem-based learning environment. HSDM held calibration meetings for the tutorial leaders, to give them the basic concepts and learning objectives, before the Oral Health Session; however, since some of the leaders were not able to attend the calibration meetings and some were more familiar than others with the problem-based tutorial format, some students felt their tutorial leaders were not as effective as they might have been. 
The future direction for this program involves further developing the oral health topics throughout the curriculum and measuring evidence of impact in the collaborative learning experience. This project could have a significant effect on patient care outcomes. A medical professional who is aware of the link between oral and systemic health and mindful of the societal and biological consequences of poor oral health can provide a higher level of care to patients.

\section{Conclusion}

In this study, the Oral Health Sessions in the medical curriculum helped to increase student awareness and understanding of oral health. As patient care involves multidisciplinary and interprofessional environments with a wide array of health care providers, curricular directions for medical school should explore an education model that incorporates oral health.

\section{References}

1 Hendricson WD, Cohen PA: Oral health care in the 21st century: implications for dental and medical education. Acad Med 2001;76: 1181-1206.

2 Formicola AJ: Dentistry and medicine, then and now. J Am Coll Dent 2002;69:30-34.

3 Vargas CM, Isman RE, Crall JJ: Comparison of children's medical and dental insurance coverage by sociodemographic characteristics, United States, 1995. J Pub Health Dent 2002;62:38-44.

4 Cohen LA: Expanding the physician's role in addressing the oral health of adults. Am J Public Health 2012;103:408-412.

5 Hale KJ: Oral health risk assessment timing and establishment of the dental home. Pediatrics 2003;111:1113-1116.

6 Mouradian WE, Reeves A, Kim S, et.al: An oral health curriculum for medical students at the University of Washington. Acad Med 2005;80:434-442.

7 Donoff B, McDonough JE, Riedy C: Integrating oral and general health care. $\mathrm{N}$ Engl J Med 2014;371:2247-2249.

8 Krol DM: Educating pediatricians on children's oral health: past, present, and future. Pediatrics 2004;113:e487-e492.
9 Mouradian WE, Reeves A, Kim S, et al: A new oral health elective for medical students at the University of Washington. Teach Learn Med 2006; 18:336-342.

10 Ferullo A, Silk H, Savageau JA: Teaching oral health in U.S. medical schools: Results of a national survey. Acad Med 2011;86:226-230.

11 Wilder RS, O'Donnell JA, Barry JM, et al: Is dentistry at risk? A case for interprofessional education. J Dent Educ 2008;72:231-237.

12 Haden NK, Hendricson WD, Kassebaum DK, et al: Curriculum change in dental education, 2003-2009. J Dent Educ 2010;74:539-557.

13 Mabry CC, Mosca NG: Interprofessional educational partnerships in school health for children with special oral health needs. J Dent Educ 2006;70:844-850.

14 Migliorati CA, Madrid C: The interface between oral and systemic health: the need for more collaboration. Clin Microbiol Infect 2007;13(suppl 4):11-16.

15 Owens JB, Wilder RS, Southerland JH, et al: North Carolina internists' and endocrinologists' knowledge, opinions, and behaviors regarding periodontal disease and diabetes: need and opportunity for interprofessional education. J Dent Educ 2011;75:329-338.
16 Offenbacher S, Jared HL, O’Reilly PG, et al: Potential pathogenic mechanisms of periodontitis associated pregnancy complications. Ann Periodontol 1998;3:233-250.

17 Mattila KJ, Asikainen S, Wolf J, et al: Age, dental infections, and coronary heart disease. J Dent Res 2000;79:756-760.

18 Genco RJ: Periodontal disease and risk for myocardial infarction and cardiovascular disease. Cardiovasc Rev Rep 1998;19:34-40.

19 Hujoel PP, Drangsholt M, Spiekerman C, et al: Periodontal disease and coronary heart disease risk. JAMA 2000;284:1406-1410.

20 Yoon AJ, Cheng B, Philipone E, et al: Inflammatory biomarkers in saliva: assessing the strength of association of diabetes mellitus and periodontal status with the oral inflammatory burden. J Clin Periodontol 2012;39: 434-440.

21 Petersen P: Strengthening of oral health systems: oral health through primary health care. Med Princ Pract 2014;23;3-9.

22 Mumghamba EG: Integrating a primary oral health care approach in the dental curriculum: a Tanzanian experience. Med Princ Pract 2014;23:69-77.

23 Rifai N, Ridker PM: Inflammatory markers and coronary heart disease. Curr Opin Lipidol 2002;13:383-389. 